\title{
Open synovectomy treatment for intra- and extraarticular localized pigmented villonodular synovitis of the knee: a case report
}

Daoliang $\mathrm{Xu}^{1}$, Jianxia Wen ${ }^{2}$, Shisi Zhang ${ }^{1}$ and Xiaoyun Pan ${ }^{1 *}$

\begin{abstract}
Background: Pigmented villonodular synovitis (PVNS) is a rare, benign, proliferative neoplastic process that commonly affects synovial-lined anatomic spaces. The diffuse type (DPVNS) is characterized by invasion of the entire joint synovium, while the localized type (LPVNS) is characterized by a relatively normal synovial appearance. This report describes a unique case of massive intraarticular LPVNS with an extraarticular extension through the lateral patellar retinaculum. No similar cases have been found in the literature.

Case presentation: A 58-year-old woman had a history of hyperuricemia and knee trauma and presented with unilateral knee acute swelling and pain symptoms with sudden onset. Recent expansion of the LPVNS caused the development of a tender palpable soft tissue mass in the anterolateral aspect of the knee and acute reduced mobility. Preoperative magnetic resonance imaging of the knee revealed the presence of only the soft tissue mass and mild degenerative changes. Open synovectomy was performed successfully to excise the mass. Intraoperatively, macroscopic features of the bright brown inflamed synovium suggested LPVNS, which was confirmed histopathologically. Postoperatively, the symptoms of limited mobility and pain were appreciably relieved. Recurrence was not observed during the clinical follow-up at 1,6 or 18 months after surgery.

Conclusions: Here, we report the unique case of localized pigmented villonodular synovitis of the knee in a misdiagnosed patient with intra- and extraarticular lesion, which might be attributed to the history of knee trauma and the focal defect of the lateral patellar retinaculum. Open synovectomy effectively relieved the symptoms of limited mobility and pain and no recurrence was observed prior to 18 months postoperatively. To reduce misdiagnosis, MRI examinations are recommended for all patients suspected of having PVNS, including those who have a history of hyperuricemia.
\end{abstract}

Keywords: Case report, Pigmented villonodular synovitis, Intraarticular, Extraarticular, Synovectomy

\footnotetext{
* Correspondence: Xiaoyunpan@126.com

1 Department of Orthopaedic Surgery, Second Affiliated Hospital and Yuying

Children's Hospital of Wenzhou Medical University, 109 Xueyuan Xi Road,

325027 Wenzhou, Zhejiang, China

Full list of author information is available at the end of the article
}

(c) The Author(s). 2021 Open Access This article is licensed under a Creative Commons Attribution 4.0 International License, which permits use, sharing, adaptation, distribution and reproduction in any medium or format, as long as you give appropriate credit to the original author(s) and the source, provide a link to the Creative Commons licence, and indicate if changes were made. The images or other third party material in this article are included in the article's Creative Commons licence, unless indicated otherwise in a credit line to the material. If material is not included in the article's Creative Commons licence and your intended use is not permitted by statutory regulation or exceeds the permitted use, you will need to obtain permission directly from the copyright holder. To view a copy of this licence, visit http://creativecommons.org/licenses/by/4.0/. The Creative Commons Public Domain Dedication waiver (http://creativecommons.org/publicdomain/zero/1.0/) applies to the data made available in this article, unless otherwise stated in a credit line to the data. 


\section{Background}

Pigmented villonodular synovitis is a rare benign tumour of the synovium, characterized by the presence of synovial proliferation and haemosiderin deposition within synovial-lined anatomic spaces [1, 2]. As PVNS is a monoarticular process, it mainly affects the knee $(\sim 70 \%$ of cases), followed by the hip ( $\sim 20 \%$ of cases), ankle, shoulder, and elbow [3-5]; in these joints, PVNS causes joint swelling, pain, and stiffness. Individuals in the third or fourth decade of life appear to be more susceptible to this aggressive disease. The annual incidence of PVNS is estimated of $2-8$ cases per million in the general population with male predominance, although some studies have shown there are no differences between gender [6$10]$. Without treatment, PVNS can cause severe degenerative changes and osteoarthritis [11]. Even after treatment, the recurrence rate of PVNS ranges from 14 to $55 \%$ [12].

Although the exact pathogenesis of PVNS remains unclear, this disease is presumably closely related to trauma, intraarticular bleeding, and inflammation [13]. Due to the highly variable clinical presentation of PVNS, an accurate diagnosis is extremely difficult to achieve. Advanced imaging modalities, such as magnetic resonance imaging (MRI), are considered the most sensitive approaches for the assessment of suspected PVNS. Soft masses with low signal intensity and "blooming artifact" on MRI scans appear to be pathognomonic of PVNS [1, $14,15]$. However, histopathology remains the gold standard tool to confirm the diagnosis. Surgical treatment for PVNS is considered as the standard treatment for these lesions; conservative treatments, such as radiation therapy, are also available. An in-depth understanding of the extent of the disease is needed to select the most appropriate treatment, as the two types of PVNS require different treatments. Currently, PVNS is classified as diffuse (DPVNS) or localized (LPVNS) [16]. The two types of PVNS can be further categorized as intraarticular or extraarticular. Despite the histological similarity, there are differences between the types in clinical presentation, prognosis, and response to treatment $[17,18]$.

Here, we describe a patient who had massive intraarticular LPVNS with an extraarticular extension through the lateral patellar retinaculum; the lesion was completely excised in open synovectomy.

\section{Case presentation}

A 58-year-old woman who did not have a recent history of injury presented to our orthopaedic clinic with a tender palpable soft tissue mass in the anterolateral aspect of the left knee and acute reduced range of motion (ROM). The patient had a history of hyperuricemia for nearly 30 years and experienced knee trauma approximately 20 years ago.
She complained of recurrent swelling and pain in the knee, which may have been misdiagnosed as gouty arthritis at the local community hospital because of similar symptoms. The advised treatment based on the symptoms, including colchicine and nonsteroidal antiinflammatory drugs, partially relieved the patient's symptoms. The physical examination showed moderate, recurrent swelling of the left knee without surrounding warmth, as well as a tender mass growing slowly in the anteroinferior aspect of the left knee. Because of pain, the patient's ROM in flexion had decreased considerably $\left(30^{\circ}-70^{\circ}\right.$ in the left knee, compared with $0^{\circ}-110^{\circ}$ in the right knee). The results of the laboratory tests for both trioxypurine and infection were within the respective normal limits. The MRI examination of the left knee revealed a massive intraarticular soft tissue lesion (measuring $58 \times$ $32 \times 46 \mathrm{~mm}$ ) that replaced the normal Hoffa fat pad and extended through the lateral patellar retinaculum (Fig. 1a and c). Moreover, the lobulated mass had a wellcircumscribed margin and exhibited focal heterogeneous hypointensity representing the blooming artifact from haemosiderin (Fig. 1b), which is regarded as the pathognomonic appearance of PVNS on MRI. Only mild degenerative changes and joint effusion were observed, without tophus or bone erosion.

Based on the MRI findings, it was considered impossible to completely remove the mass lesion. Therefore, open excision was selected as the surgical treatment. A 13-cm median incision was made, and synovectomy was performed successfully. A bright brown inflamed lobulated synovium was observed intraoperatively (Fig. 2a). Neither bone erosion nor diffuse soft tissue lesions were observed, suggesting a diagnosis of LPVNS. The final diagnosis was further confirmed by postoperative histological analysis, the results of which were consistent with LPVNS: multinucleated giant cells with no atypical features and an abundance of macrophages loaded with haemosiderin.

Postoperatively, the patient was satisfied with the substantial improvement of knee $\operatorname{ROM}\left(5^{\circ}-100^{\circ}\right)$. At the 1 , 6 and 18-month follow-ups, the patient had no pain and exhibited full restoration of knee ROM, with neither complications nor radiological recurrence (Fig. 3).

\section{Discussion}

Early-stage PVNS is challenging to diagnose because the symptoms of PVNS are atypical. Patients commonly present with symptoms of pain, swelling, instability, reduced ROM, and/or a palpable mass [19]. Other conditions (e.g., various types of synovitis and arthritis, degenerative changes, and soft tissue tumours) need to be excluded before PVNS can be diagnosed. Although the "blooming artifact" on MRI is regarded as the pathognomonic appearance of PVNS, and MRI has therefore 

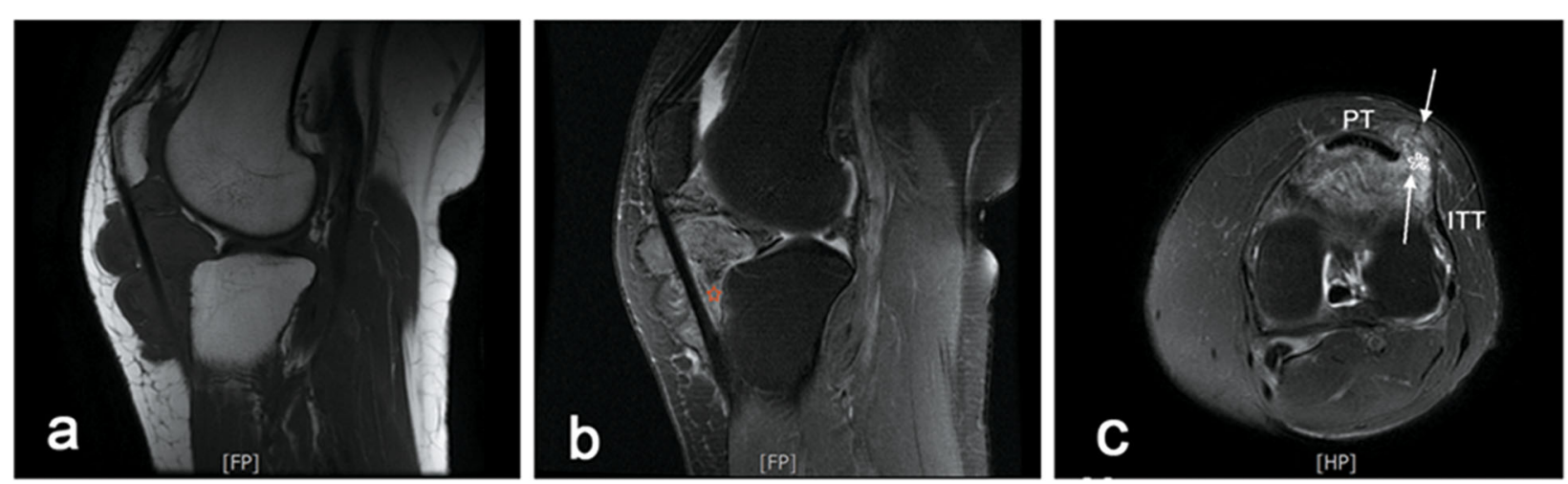

Fig. 1 Preoperative MRI scans. a LPVNS manifested as a circumscribed and lobulated infrapatellar mass with an extra-articular extension through patellar tendon on sagittal T1-weighted images. b The pathognomonic appearance of PVNS, a "blooming artifact" caused by hemosiderin deposition (red pentastar), was observed on sagittal T2-weighted images. c Axial images revealed that extra-articular mass developed on both sides of the lateral patellar retinaculum, through a focal defect (asterisk), with a superficial component (arrowhead) and a deep component (arrowhead). ITT: Indicates iliotibial tract; PT: patellar tendon

become the modality of choice for diagnosis, a definitive diagnosis can only be established histopathologically [7, 20]. Patients may tolerate symptom progression for an extended period of time before seeking treatment [2123]; it has been reported that the mean duration from the initial onset of PVNS to diagnosis is 2.9 years [2]. Patients between 30 and 50 years of age are more susceptible to developing LPVNS [18]. In the case reported here, the first symptom (a swollen left knee without pain) occurred when the patient was approximately 41 years of age. However, 17 years passed before she was accurately diagnosed with LPVNS. LPVNS is less aggressive than DPVNS, over a long time, the symptoms of the patient remained mild and progressed slowly; in the absence of imaging data, the lesion was not suspected or was misdiagnosed as a process of nonspecific presentation, such as gouty arthritis, rheumatoid arthritis, hemophilia, angiomas, synovial neoplasias, and other
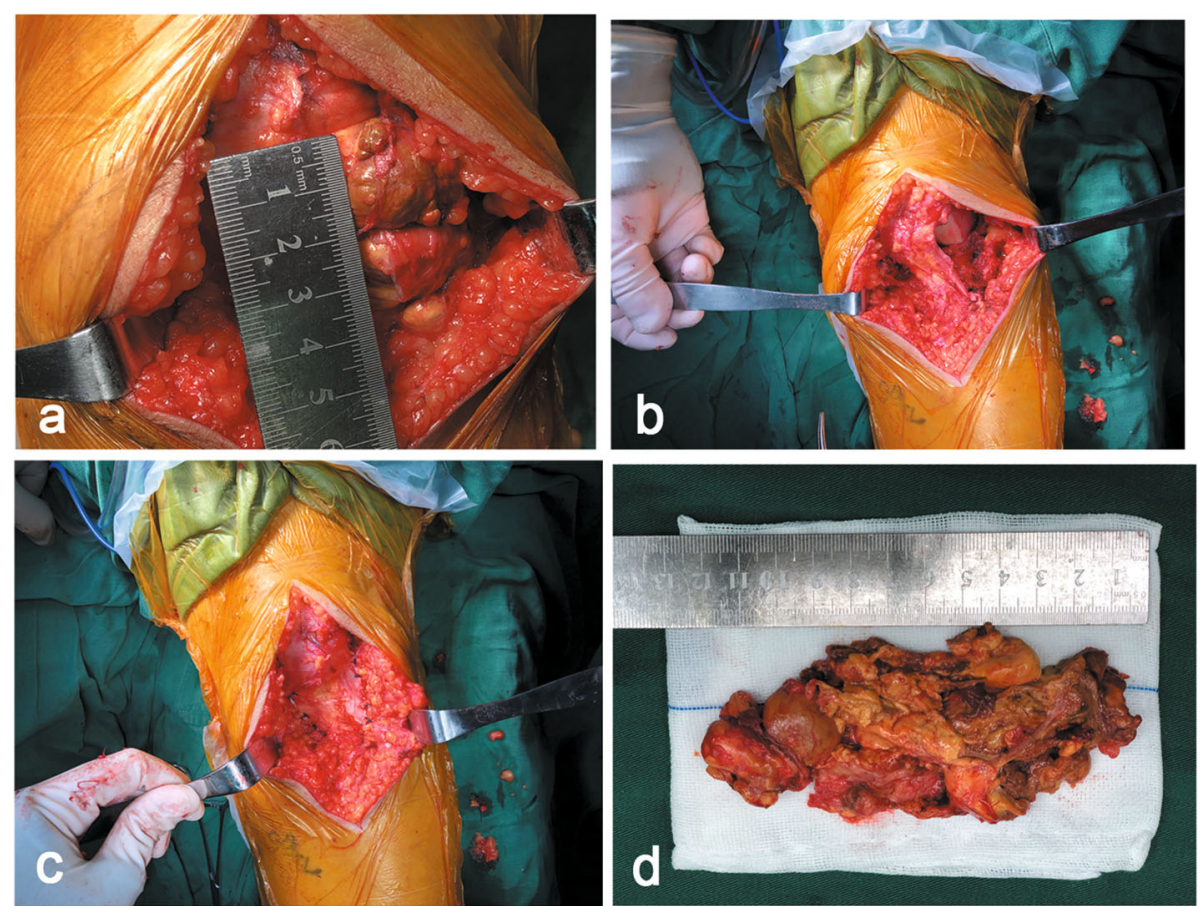

Fig. 2 Intraoperative findings. a Exposure of the extra-articular mass originating from the lateral patellar retinaculum. (b. c) As the abnormal synovium was excised completely, the focal defect lateral patellar retinaculum was repaired. $\mathbf{d}$ The $13 \mathrm{~cm}$ median incision was sutured with skin staples 

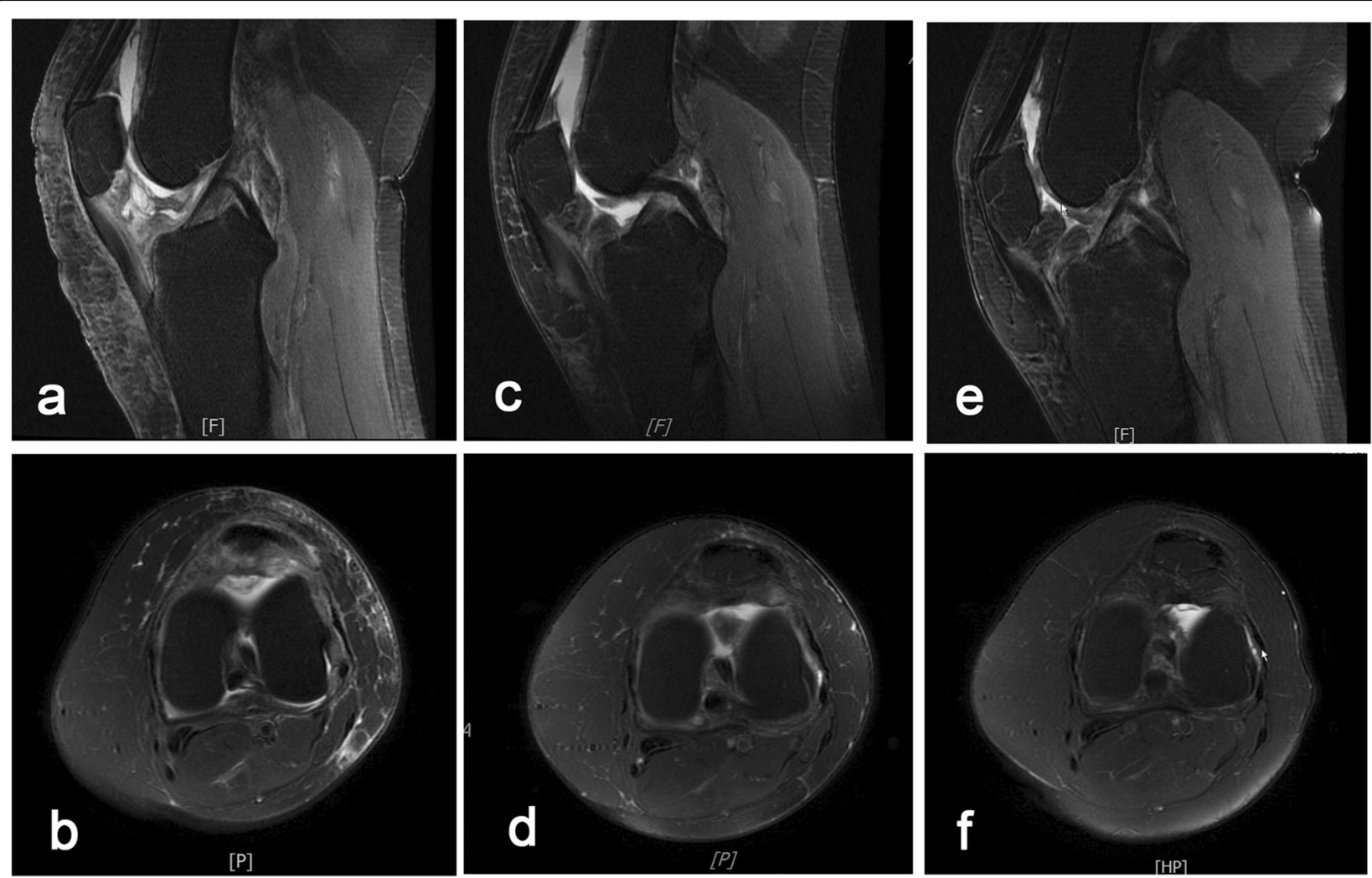

Fig. $3 \mathrm{MRI}$ scan at the follow-up. a, b No recurrence was observed on either the sagittal or axial MRI scans at the 1-month follow-up. c-f No recurrence was observed at the 6- or 18-month follow-up

inflammatory processes; as well as the history of hyperuricemia, led to a misdiagnosis at the local community hospital. No tophus or bone erosion was observed, either on preoperative MRI scans or intraoperatively. Coincidentally, symptomatic treatment including nonsteroidal anti-inflammatory drugs provided effective symptom relief, which also contributed to the delay in the accurate diagnosis. Ultimately, the diagnostic delay led to a late treatment, while the early diagnosis may contribute to the better clinical evaluation, especially in improving the postoperative discomfort and limited range of motion, MRI examination is capable of showing the typical characteristic of PVNS and plays a crucial role in the initial diagnosis. Moreover, preoperative MRI is used to identify the intra- and extraarticular lesion which is conducive to avoid incomplete excision of the tumor leading to recurrence. Therefore, before PVNS is confirmed, we recommend that MRI examinations are performed in all patients suspected of having PVNS with repeated joint swelling, pain, joint mobility limitation and joint effusion, including those who have a history of hyperuricemia.

In the knee, LPVNS typically presents as a focal mass, frequently in the anterior compartment [18]. The mass occasionally extrudes into the articular cavity and can vary in diameter from a few millimetres to $3 \mathrm{~cm}[20,24]$. The mechanical symptoms of LPVNS vary in relation to the lesion size and location [25]. Although LPVNS tends to exhibit a more slowly destructive course, focal bone destruction has been observed in some patients. In the patient in our study, the lesion features were notable. The intraand extraarticular mass, measuring $125 \times 49 \mathrm{~mm}$ (in vitro, Fig. 2d), is the largest reported thus far; this large size may be related to the relatively long course of the disease. The mass was located in the anteroinferior joint space with extraarticular extension through the lateral patellar retinaculum (Fig. 2a), which may have been associated with the focal defect of the lateral patellar retinaculum [26]; this condition was particularly likely to occur in the patient in our study, as she experienced localized left knee trauma 20 years ago. However, only mild degenerative changes and joint effusion were observed. The anteroinferior joint space is relatively large and the intraarticular mass can herniate through the focal defect of the lateral patellar retinaculum during knee flexion. Since no similar PVNS cases were found in the literature, our article is - to our knowledge - the first to report a case of massive intraarticular LPVNS. 
Currently, there is no standard method for nonsurgically observing LPVNS. The eradication of all aberrant synovial tissue in symptomatic patients is considered a suitable treatment option for LPVNS, as it effectively relieves pain and prevents local recurrence. Nevertheless, the optimal type of resection and whether adjuvant therapy should be used remains controversial [27]. Open synovectomy is routinely performed for extraarticular extension of LPVNS when full excision cannot be achieved with an arthroscope $[20,28]$. However, open excision may lead to postoperative muscle weakness and an increased risk of osteoarthritic changes. With advances in arthroscopy, all-arthroscopic total synovectomy has been shown to be equally effective [20, 29-31]. In addition, the combination of the two techniques using a posterior open and anterior arthroscopic approach may be ideal when commonly used portals cannot be used to completely excise the posterior abnormal synovial [32]. In recent years, some research has suggested that it is necessary to excise some otherwise normalappearing fat and areolar tissue with the synovium in cases of recurrence [33]. In general, the appropriate extent of excision should be determined on the basis of the type of PVNS, the presence of extraarticular extensions, and the experience of the surgeon. In addition, conventional radiotherapy, as well as radiosynoviorthesis, is considered for patients with large and even recurrent diffuse forms of the disease [34]. Preoperatively, although the patient had been recommended to receive radiosynoviorthesis 6-8 weeks after surgery, she declined to accept the adjuvant therapy because of the concerns about the potential side effects of the radiopharmacon, Fortunately, both intraoperative findings and the postoperative MRI ensured that no residual PVNS was found. So far, the complete surgical excision without radiation therapy is satisfactory in the present case. Nevertheless, PVNS still has a certain rate of recurrence; in some cases, recurrence occurs even after 16 years postoperatively [35]. The diffuse form of the disease, incomplete resection, the lesions being located in locations difficult to access, the surgeon having limited experience and skills, and the administration of adjuvant therapy after surgery have been identified as the major risk factors for recurrence [27]. Approximately two-thirds of local recurrences are diagnosed within postoperative 2 years, while less than $10 \%$ of recurrences are found after 3 years, and it is recommended that follow-up MRI scans are performed every 6 months during the first 3 years to detect local recurrences effectively [36]. In this patient, we successfully performed open complete excision. Symptom relief was achieved, and no recurrence was observed during the subsequent followup (Fig. 3); however, the long-term curative effect remains to be assessed.

\section{Conclusions}

To reduce the occurrence of misdiagnosis, MRI examinations are recommended for all patients suspected of having PVNS, including those who have a history of hyperuricemia. Early diagnosis with prompt surgical treatment may lead to favourable recovery.

\section{Abbreviations \\ PVNS: Pigmented villonodular synovitis; DPVNS: Diffuse pigmented villonodular synovitis; LPVNS: Localized pigmented villonodular synovitis; ROM: Range of motion; MRI: Magnetic Resonance Imaging}

\section{Acknowledgements}

The authors report no benefits, grants, or assistance from any party.

The patient was informed that data from the case would be submitted for publication and she provided her consent.

\section{Authors' contribution}

DLX and XYP participated in the diagnosis and treatment of the patient, provided follow-up, acquired clinical data, drafted and reviewed the manuscript. SSZ and JXW conducted investigations, reviewed literature, and assisted in polishing the manuscript for final publication. All of the authors read and approved the final manuscript.

\section{Funding}

The project was only funded by Zhejiang Medicine and Health Technology Program $(2,020,375,602)$.

\section{Availability of data and materials}

The datasets used and analysed during the current study are available from the corresponding author on reasonable request.

\section{Ethics approval and consent to participate}

This article does not contain any studies with human participants or animals performed by any of the authors.

\section{Consent for publication}

The written consent to publish images or other personal or clinical details of participants was obtained from the patient.

\section{Competing interests}

The authors declare that they have no conflict of interest.

\section{Author details}

'Department of Orthopaedic Surgery, Second Affiliated Hospital and Yuying Children's Hospital of Wenzhou Medical University, 109 Xueyuan Xi Road, 325027 Wenzhou, Zhejiang, China. ${ }^{2}$ Department of Gastrointestinal Surgery, The First Affiliated Hospital of Wenzhou Medical University, Wenzhou, Zhejiang, China.

Received: 8 May 2020 Accepted: 21 December 2020

Published online: 07 January 2021

\section{References}

1. Murphey MD, Rhee JH, Lewis RB, Fanburg-Smith JC, Flemming DJ, Walker EA. Pigmented villonodular synovitis: radiologic-pathologic correlation. Radiographics: a review publication of the Radiological Society of North America Inc. 2008;28(5):1493-518.

2. Ottaviani S, Ayral X, Dougados M, Gossec L. Pigmented villonodular synovitis: a retrospective single-center study of 122 cases and review of the literature. Semin Arthritis Rheum. 2011:40(6):539-46.

3. Shah SH, Porrino JA, Green JR 3rd, Chew FS. Bilateral pigmented villonodular synovitis of the knee. Radiology case reports. 2015;10(4):56-60.

4. O'Connell JX. Pathology of the synovium. Am J Clin Pathol. 2000;114(5): 773-84.

5. Xie GP, Jiang N, Liang CX, Zeng JC, Chen ZY, Xu Q, Qi RZ, Chen YR, Yu B. Pigmented villonodular synovitis: a retrospective multicenter study of 237 cases. PloS one. 2015;10(3):e0121451.

6. Abdul-Karim FW, el-Naggar AK, Joyce MJ, Makley JT, Carter JR. Diffuse and localized tenosynovial giant cell tumor and pigmented villonodular 
synovitis: a clinicopathologic and flow cytometric DNA analysis. Human pathology. 1992;23(7):729-35.

7. Flandry F, Hughston JC. Pigmented villonodular synovitis. The Journal of bone joint surgery American volume. 1987;69(6):942-9.

8. Flandry F, Hughston JC, McCann SB, Kurtz DM. Diagnostic features of diffuse pigmented villonodular synovitis of the knee. Clinical orthopaedics and related research. 1994;298:212-20.

9. Flandry FC, Hughston JC, Jacobson KE, Barrack RL, McCann SB, Kurtz DM. Surgical treatment of diffuse pigmented villonodular synovitis of the knee. Clinical orthopaedics and related research. 1994;300:183-92.

10. Gu HF, Zhang SJ, Zhao C, Chen Y, Bi Q: A comparison of open and arthroscopic surgery for treatment of diffuse pigmented villonodular synovitis of the knee. Knee surgery, sports traumatology, arthroscopy: official journal of the ESSKA 2014, 22(11):2830-2836.

11. Gonzalez Della Valle A, Piccaluga F, Potter HG, Salvati EA, Pusso R. Pigmented villonodular synovitis of the hip: 2- to 23-year followup study. Clinical orthopaedics and related research 2001(388):187-199.

12. Fecek C, Carter KR: Pigmented Villonodular Synovitis. In: StatPearls. edn. Treasure Island (FL): StatPearls Publishing Copyright @ 2020, StatPearls Publishing LLC.; 2020.

13. Bassetti E, Candreva R, Santucci E. Pigmented villonodular synovitis of the knee: A case report. J Ultrasound. 2011;14(3):167-9.

14. Friedman T, Chen T, Chang A. MRI diagnosis of recurrent pigmented villonodular synovitis following total joint arthroplasty. HSS journal: the musculoskeletal journal of Hospital for Special Surgery. 2013;9(1):100-5.

15. Garner HW, Ortiguera CJ, Nakhleh RE. Pigmented villonodular synovitis. Radiographics: a review publication of the Radiological Society of North America Inc. 2008;28(5):1519-23.

16. Granowitz SP, Mankin HJ. Localized pigmented villonodular synovitis of the knee. Report of five cases. The Journal of bone joint surgery American volume. 1967;49(1):122-8

17. Auregan JC, Klouche S, Bohu Y, Lefevre N, Herman S, Hardy P: Treatment of pigmented villonodular synovitis of the knee. Arthroscopy: the journal of arthroscopic \& related surgery: official publication of the Arthroscopy Association of North America and the International Arthroscopy Association 2014, 30(10):1327-1341.

18. Stephan SR, Shallop B, Lackman R, Kim TW, Mulcahey MK. Pigmented Villonodular Synovitis: A Comprehensive Review and Proposed Treatment Algorithm. JBJS reviews 2016, 4(7).

19. Dines JS, DeBerardino TM, Wells JL, Dodson CC, Shindle M, DiCarlo EF, Warren RF: Long-term follow-up of surgically treated localized pigmented villonodular synovitis of the knee. Arthroscopy: the journal of arthroscopic \& related surgery : official publication of the Arthroscopy Association of North America and the International Arthroscopy Association 2007, 23(9):930-937.

20. Ogilvie-Harris DJ, McLean J, Zarnett ME. Pigmented villonodular synovitis of the knee. The results of total arthroscopic synovectomy, partial, arthroscopic synovectomy, and arthroscopic local excision. The Journal of bone joint surgery American volume. 1992;74(1):119-23.

21. Atik OS, Bozkurt HH, Ozcan E, Bahadir B, Ucar M, Ogut B, Memis L. Localized pigmented villonodular synovitis in a child knee. Eklem hastaliklari ve cerrahisi $=$ Joint diseases related surgery. 2017;28(1):46-9.

22. Sezgin EA, Atik OS. Tumors and tumor-like lesions of infrapatellar fat pad and surrounding tissues: A review of the literature. Eklem hastaliklari ve cerrahisi = Joint diseases related surgery. 2018;29(1):58-62.

23. Asik M, Erlap L, Altinel L, Cetik O. Localized pigmented villonodular synovitis of the knee. Arthroscopy: the journal of arthroscopic related surgery : official publication of the Arthroscopy Association of North America the International Arthroscopy Association. 2001;17(6):E23.

24. Calmet J, Hernandez-Hermoso J, Gine J, Jimeno F. Localized pigmented villonodular synovitis in an unusual location in the knee. Arthroscopy: the journal of arthroscopic related surgery : official publication of the Arthroscopy Association of North America the International Arthroscopy Association. 2003;19(2):144-9.

25. Flandry FC, Jacobson KE, Andrews JR. Localized pigmented villonodular synovitis of the knee mimicking meniscal injury. Arthroscopy: the journal of arthroscopic related surgery : official publication of the Arthroscopy Association of North America the International Arthroscopy Association. 1986;2(4):217-21

26. Moraux A, Bianchi S. Soft Tissue Masses of the Knee Related to a Focal Defect of the Lateral Patellar Retinaculum. 2018:37(7):1821-5.
27. Fang $Y$, Zhang $Q$. Recurrence of pigmented villonodular synovitis of the knee: A case report with review of literature on the risk factors causing recurrence. Medicine. 2020;99(16):e19856.

28. Chin KR, Barr SJ, Winalski C, Zurakowski D, Brick GW. Treatment of advanced primary and recurrent diffuse pigmented villonodular synovitis of the knee. The Journal of bone joint surgery American volume. 2002;84(12):2192-202.

29. De Ponti A, Sansone V, Malchere M. Result of arthroscopic treatment of pigmented villonodular synovitis of the knee. Arthroscopy: the journal of arthroscopic related surgery : official publication of the Arthroscopy Association of North America the International Arthroscopy Association. 2003;19(6):602-7.

30. Zvijac JE, Lau AC, Hechtman KS, Uribe JW, Tjin ATEW: Arthroscopic treatment of pigmented villonodular synovitis of the knee. Arthroscopy: the journal of arthroscopic \& related surgery : official publication of the Arthroscopy Association of North America and the International Arthroscopy Association 1999, 15(6):613-617.

31. Papamerkouriou YM, Posantzis MI, Kouremenos D, Manousakis C, Plessas SI. Arthroscopic Technique for the Treatment of Localized Pigmented Villonodular Synovitis of the Knee. Cureus. 2020;12(4):e7832.

32. Sharma V, Cheng EY. Outcomes after excision of pigmented villonodular synovitis of the knee. Clin Orthop Relat Res. 2009;467(11):2852-8.

33. Jobe CM, Raza A, Zuckerman L. Pigmented villonodular synovitis: extrasynovial recurrence. Arthroscopy: the journal of arthroscopic related surgery : official publication of the Arthroscopy Association of North America the International Arthroscopy Association. 2011;27(10):1449-51.

34. Dürr HR, Capellen CF, Klein A, Baur-Melnyk A, Birkenmaier C, Jansson V, Tiling $R$. The effects of radiosynoviorthesis in pigmented villonodular synovitis of the knee. Arch Orthop Trauma Surg. 2019;139(5):623-7.

35. Verspoor FG, Zee AA, Hannink G, van der Geest IC, Veth RP, Schreuder HW. Long-term follow-up results of primary and recurrent pigmented villonodular synovitis. Rheumatology. 2014;53(11):2063-70.

36. Capellen CF, Tiling R, Klein A, Baur-Melnyk A, Knösel T, Birkenmaier C, Roeder F, Jansson V, Dürr HR. Lowering the recurrence rate in pigmented villonodular synovitis: A series of 120 resections. Rheumatology. 2018;57(8): $1448-52$.

\section{Publisher's Note}

Springer Nature remains neutral with regard to jurisdictional claims in published maps and institutional affiliations.

Ready to submit your research? Choose BMC and benefit from:

- fast, convenient online submission

- thorough peer review by experienced researchers in your field

- rapid publication on acceptance

- support for research data, including large and complex data types

- gold Open Access which fosters wider collaboration and increased citations

- maximum visibility for your research: over $100 \mathrm{M}$ website views per year

At $\mathrm{BMC}$, research is always in progress.

Learn more biomedcentral.com/submission 